\title{
Derleme
}

Mersin Univ Saglık Bilim Derg 2021;14(2):334-341

doi: 10.26559/mersinsbd.825871

\section{Adölesanlarda umut, sağlık ve hemşirelik}

\author{
(1D)Fatma Zehra GENÇ ${ }^{1}$, (D) Naile BILGiLíi ${ }^{2}$ \\ 1Necmettin Erbakan Üniversitesi Hemşirelik Fakültesi Halk Sağlığı Hemşireliği AD \\ ${ }^{2}$ Gazi Üniversitesi Sağlık Bilimleri Fakültesi, Halk Sağlı̆̆ı Hemşireliği AD
}

\section{$\ddot{0 ̈ z}$}

Ergenlik dönemi çocukluktan erişkinliğe geçiş, bireyin değișen bedenine, duygularına ve sorumluluklarına uyum sağlayabilme sürecidir. Bu hızlı gelişim ve değişim sürecinde yaşanan stres ve zorluklar genellikle sağlıklı bir grup olarak algılanan adölesanların fiziksel ve ruh sağlığını, yaşam kalitesini, mücadele gücünü, yaşam doyumunu olumsuz etkileyebilmektedir. Bu bağlamda umut, adölesanların değişim süreci ve stresli yaşam olaylarının neden olduğu sorunlarla başa çıkmaları gerektiğinde yaşam için vazgeçilmez psikolojik kaynak olarak karşımıza çıkmaktadır. Bu düşünceden yola çıkarak derlemede; adölesanlarda umudun sağlık üzerine etkilerine ve hemşirelik yaklaşımının önemine vurgu yapmak amaçlanmıştır.

Anahtar Kelimeler: Adölesan, umut, sağlık, hemşirelik

\section{Hope, health and nursing in adolescents}

\begin{abstract}
Adolescence is the transition from childhood to adulthood, the process of adapting to a person's changing body, emotions and responsibilities. Stress and difficulties experienced in this rapid development and change process may adversely affect the physical and mental health, quality of life, struggle power, life saturation of adolescents who are perceived as healthy groups. In this context, hope comes across as an indispensable psychological resource for life when adolescents need to deal with the process of change and problems caused by stressful life events. Based on this idea, in the review; it is aimed to emphasize the effects of hope on health in adolescents and the importance of nursing approach.
\end{abstract}

Key words: Adolescent, hope, health, nursing

Başvuru Tarihi: 14.11 .2020

Kabul Tarihi: 15.02 .2021

Sorumlu Yazar: Fatma Zehra Genç, Necmettin Erbakan Üniversitesi, Hemşirelik Fakültesi, Halk Sağlı̆̆ı Hemşireliği Anabilim Dalı, Tlf: +90 033232040 49, E-posta: fgenc@erbakan.edu.tr

Not: $\mathrm{Bu}$ çalışmanın özet hali 3. Uluslararası 21. Ulusal Halk Sağlığı Kongresinde Antalya'da 26-30 Kasım 2019'da poster bildiri olarak sunulmuştur (https://uhsk.org/2019/images/KONGRE2019.pdf: 1078-1079). 


\section{Giriş}

Adölesan dönemi çocukluk çağının bitimi, yetişkin döneme geçişin başladığı hızlı büyüme ve gelişme ile karakterize bir dönemdir. ${ }^{1}$ Dünya Sağlık Örgütü'ne (DSÖ) göre adölesan grubu 10-19 yaş aralığını kapsamakta ve 10-14 yaş aralığı genç adölesan olarak tanımlanmaktadır. Dünyada nüfusunun \%42'si 25 yaşın altında olup, bu gençlerin yaklaşık 1,2 milyarı 10-19 yaşları arasındaki adölesanlardan oluşmaktadır.,23 Türkiye de genç nüfus oranı fazla olan ülkelerden biri olup, genç nüfus toplam nüfusun \%15.8'ini oluşturmaktadır. Genç nüfusun, \%51.2'sini erkek nüfus, \%48.8'ini ise kadın nüfus oluşturmaktadır. ${ }^{4}$

Ergenlik dönemi çocukluktan erişkinliğe geçiş, bireyin değișen bedenine, duygularına ve sorumluluklarına uyum sağlayabilme sürecidir. Bu hızlı gelişim ve değişim sürecinde yaşanan stres ve zorluklar sağlıklı grup olarak algılanan adölesanların fiziksel ve ruh sağlığını, yaşam kalitesini, mücadele gücünü, yaşam doyumunu olumsuz etkileyebilmektedir.3,5 Bu bağlamda umut, adölesanların değişim sürecinde güç kaynağı olarak karşımıza çıkmaktadır. Umut kavramı, psikososyal uyum ve yaşam kalitesi için de anahtar olup günümüzde psikoloji, felsefe, hemşirelik ve tıp gibi pek çok disiplinin ilgilendiği bir konudur.6,7 Sağlık ve hastalık sürecinde bireyi etkileyen her kavram, hemşireliği ilgilendirir ve hemşirelik bakımını planlamak ve yön vermek için kullanılır. Sağlığı ve hastalığı etkileyen umut kavramı hakkında bilgi sahibi olmak, bireylere verilen sağlı hizmetini belirleme ve sunmada ön plana çıkmaktadır. $\mathrm{Bu}$ derlemede adölesan sağlığında umudun yeri, önemi, ölçümü, sağlığa olan etkileri, umudun hemşirelik açısından önemi açıklanmakta ve literatürde yer alan çalışmaların sonuçları yorumlanmaktadır.

\section{Adölesanlarda umut kavramı}

Umut, arzulamak, arzuları eyleme geçirmek için yollar bulmak ve vazgeçmemektir. Snyder8 umudu "arzulanan hedeflere giden yollar üretme kapasitesi, bu yolları kullanarak harekete geçme güdüsü ve alternatif yollar üretmek için kendini motive etme yeteneği" olarak tanımlamaktadır. İnsan yaşamında önemli yeri olan umut, anlık zorluklarla mücadele edebilme ve üzüntü durumunu üstünden atabilmede insana güç veren iyileştirici bir faktördür. ${ }^{9}$ Umut etme bireyler için zorluklar karşısında pes etmeden geleceklerini planlamaları ve inşa etmelerinde bir gereksinim olup, dinamik, yaşamın temeli, gelecek odakl, bireysel olarak anlamlı ve öznel, amaç odaklı bir terim olarak ifade edilmektedir. ${ }^{10}$ Umut, bireyin enerji derecesini belirtir ve bu enerji bireyleri motive eder. Umutsuzluk ise, insanların problemlerinin çözümü ya da arzu ettikleri durumlara ulaşılması için, bireysel olarak hiçbir seçeneğinin olmadığı ve hedeflerine ulaşabilmek için bireysel enerjilerini harekete geçiremedikleri duygusal bir durum olarak karşımıza çıkmaktadır. ${ }^{11}$

Umut literatürde farklı disiplinler tarafından, birçok değişkenlerle birlikte ele alınmıştır. Literatürde sınav kaygısı, problem çözme, öz yeterlik, algılanan sosyal destek, sosyodemografik değişkenler, kişilik özellikleri, psikolojik sağlamlık, iyi oluş, öğrenilmiş güçlülük gibi değişkenlerle birlikte değerlendirilmiştir.12-14 Umut düzeyi yüksek bireylerin kendilerini "sorumluluk sahibi, gelişmeye açık, sakin, kararlı, planlı, mantıklı, neşeli ve sosyal, uyumlu, sabırlı, kafasına koyduğunu yapan, yardımsever, rahat, her problemin bir çözümü olduğunu düşünen, girişimci" olarak tanımladıkları; umut düzeyi düşük bireylerin ise kendilerini "kararsız, hırslı olmayan, kendine güvensiz, duygusal yönden dengesiz, gerçekçi düşünmesine ve doğru karar vermesine engel olacak kadar duygusal, ailelerinin görüş ve kararlarını kendilerininkinden önemli gören, planı bozulduğunda ne yapacağını bilemeyen" kişiler olarak tanımladıkları görülmektedir. ${ }^{15}$

$$
\text { Çankaya ve Meydan }{ }^{16}
$$
çalışmasında umut değişkeninin ergenlerin mutluluk düzeylerinin anlamlı bir yordayıcısı olduğunu tespit etmiştir. Umut, fiziksel ve ruhsal sağlığın farklı yönleri ile bağı olan ve olası olumsuz olaylara karşı tampon görevi gören psikolojik sağlığın önemli bir boyutudur. Weis ve Speridakos ${ }^{17}$ umut artırma stratejilerinin umutluluğu arttırma, yaşam doyumunu arttırma ve katılımcılar arasında psikolojik sıkıntıyı azaltma ile ilişkili olup olmadığını belirlemek 
için meta-analiz çalışması yapmıştır. $\mathrm{Bu}$ çalışmada, umudu artırıcı müdahalelerin umudu arttırdığı ve beraberinde yaşam doyumunun artmasında da etkili olduğu fakat psikolojik stresin azalmasına katkıda bulunmadığı tespit edilmiştir. Yarcheski ve Mahon $^{7}$ umut çalışmalarının belirleyicilerine yönelik bir meta-analiz çalışması yürütmüștür. $\mathrm{Bu}$ çalışmada, pozitif duygulanımın, yaşam doyumunun, iyimserliğin, benlik saygısının ve sosyal desteğin umudun en güçlü belirleyicileri olduğu tespit edilmiştir. Ek olarak çalışmada depresyon orta etki düzeyine; olumsuz duygulanım, stres, akademik başarı ve şiddet düşük etki düzeyine; cinsiyet ise çok düşük etki düzeyine sahip umudun belirleyicileri olarak bulunmuştur.

Hammer ve ark. 6 "hemşirelik araştırmalarında umudun anlamı: bir metasentez" başlıklı çalışmalarında, hasta ve sağlıklı insanlar tarafindan algılanan umut ile ilgili hemşirelik araştırmalarını değerlendirmiştir. $\quad \mathrm{Bu}$ meta-sentez çalışmasında umudun boyutlarını gösteren altı metafor saptanmıştır. Bunlar; umut içinde yaşamak-bir varlık boyutu; bir şey olma/yapma umuduyla-yapma boyutu; ufukta bir ışık olarak umut-bir boyut olma; insan-insan ilişkisi olarak umut-ilişkisel boyutu; umut; umutsuzluk ve çaresizlikdiyalektik boyutu; bir öfke etkisi olarak umut-durumsal ve dinamik bir boyuttur.

\section{Adölesanlarda umudun ölçülmesi}

Birçok ülkede umudu ölçmeye yönelik ölçekler geliştirilmiş olmasına rağmen Türkiye'de bu amaçla geliştirilen ve uyarlanan ölçekler sınırlıdır. Umut konusu yaygin olarak umutsuzluk temel alınarak ve Beck Umutsuzluk Ölçeği kullanılarak ölçülmeye ve değerlendirilmeye çalışılmaktadır. ${ }^{11}$ Umudu doğrudan belirlemek amacı ile Snyder ve ark.18 (1991) tarafından geliştirilen "Sürekli Umut Ölçeği", Tarhan ve Balcanlı1 ${ }^{19}$ tarafından Türkçe 'ye uyarlanmıştır ve ölçeğin üniversite öğrencileri için kullanılabileceği belirtilmektedir.

Umudu ölçmek için adölesan grubu da içeren (8-16 yaş) "Çocuklarda Umut Ölçeği" Synder ve ark. $^{20}$ (1997) tarafindan geliştirmiş olup, ölçeğin Türkçeye uyarlaması Atik ve Kemer21 (2009) tarafından yapılmıştır. Hinds ${ }^{22}$ (1984) tarafından ergenlerin geleceğe yönelik olumlu beklentilerini belirlemek amaciyla "Ergenler için Umutluluk Ölçeği" geliştirilmiştir ve ölçeğin Türkçeye uyarlaması Esenay ve Conk $^{23}$ (2012) tarafından yapılmıştır. Ölçek hem sağlıklı hem kanserli ergenlerde kullanılmaktadır. Geç ergenlik dönemini kapsayan $18-26$ yaş aralığı için Schrank ve ark. $^{24}$ (2011) tarafından geliştirilen "Bütünleyici Umut Ölçeği" mevcut olup, Türkçeye uyarlaması Sarıçam ve Akın ${ }^{25}$ (2013) tarafından yapılmıştır. Ayrıca Aslan ve ark. ${ }^{26}$ tarafından Türkçe 'ye çevrilen "Herth Umut Ölçeği" de kullanılmaktadır. Herth ${ }^{27}$ (1992) tarafından geliştirilen ve geçerlik güvenirlik çalışmaları akut, kronik ve terminal dönemdeki hastalar üzerinde yapılan ölçeğin Türkçe versiyonunun geçerlik ve güvenirlik çalışmaları da kanserli hastalar üzerinde gerçekleştirilmiştir.

Adölesanlarda umudun sağllk üzerine etkileri ve hemşirelik yaklaşımı

Umut, umutsuzluğa karşı çıkma, acı verici kederi önleme, iyileşmek için ihtiyaç duyulan ruhsal gücü enerjiyi hareketlendirme, pozitif bir gelecek beklentisi içinde olma, fiziksel kötüleşmeye ve ölüme bireysel daveti önlemek için ihtiyaç duyulan bir kavramdır. Gerçekliğin reddi olmayıp, diğer olasılıklar ışığında gerçekliğin sürekli olarak yeniden değerlendirilmesinin bir parçasıdır. Bu bağlamda sağlık alanında umut çoğunlukla kanser, talasemi, madde bağımlılığı gibi süreğen sağlık sorunları olmak üzere diğer bazı sağlık problemlerine ilişkin bir değişken olarak kullanılmıştır. ${ }^{28-34}$

Dixson ve ark. ${ }^{35}$ yaptığı bir çalışmada umut ve ergenlikte uyumsal işlevsellik ile ilişkili çeşitli psikolojik ve eğitimsel değişkenler arasındaki ilişkiyi incelemiştir. Düşük umut, algılanan yüksek stres ve benlik saygısı ile ilişkili; yüksek umut, yüksek akademik algı ve düşük stres ile ilişkili olduğu bulunmuştur. Yapılan bu çalışmada umudun akademik (akademik benlik kavramı, akademik yatırım ve akademik başarı) ve psikolojik (gelecekteki sonuçların değerlendirilmesi, algllanan yaşam şansları, algılanan stres ve benlik saygisı) risklerin 
belirlenmesinde yararlı bir değişken olabileceği gibi ergenlikte yaşanabilecek sorunlara müdahale için potansiyel bir yol olabileceği saptanmıştır.

Zlotnick ve ark.36, "ergenlerin irksal ve etnik öz kimliğinin umut üzerindeki etkisi" konulu çalışmasında genel umut düzeyi ve umudun iki bileșeni "umut-aracısı" (kişinin hedeflere ulaşma yeteneği öngörme ve inanma yeteneğine sahip olma) ve "umutyolu" (hedefe ulaşmaya yol açan stratejiler geliștirme yeteneği) ile benlik saygısı ve aile sosyoekonomik statüsü tüm gruplarda benzer ilișkiler sergilemekle birlikte, etnik kökenle olan ilişkilerinde belirgin farklılıklar göstermiştir. Düşük umut düzeyinin depresyon, düşük refah ve düşük benlik saygısı ile bağlantılı olduğu belirtilmiştir.

García-Alandete ve ark. ${ }^{37}$ duygusal düzensizliğin ve yaşamın anlamının, ergenlerin umutsuzluğunda önemli derecede rol oynadığını belirlemişlerdir. Çalışmada yaşamın anlamı arttıkça umutsuzluk düzeyinde azalma olduğu bulunmuştur. Gerard ve ark. ${ }^{38}$ yaptığı boylamsal çalışmada ergenlerin umutları, ebeveynlerin akademik istekleri ve okula bağlılıkları depresyonla negatif ilişkili olarak belirlemiştir. McCoy ve Bowen $^{39}$ çalışmasında destekleyici ebeveyn ilişkileri, mahalle güvenliği de dâhil olmak üzere sosyal desteğin gençlerin geleceğe yönelik umutlarını artırmalarına yardımcı olabileceğini belirlemiştir. Çalışmada, sosyal desteklerin artırılmasının umudu artıracağ gibi ergenlerin okuldaki öz-yeterlik duygusunu da artıracağı bildirilmiştir.

Literatürde umut, gençlerin madde kullanımı ve bağımlılığının azalması ile ilişkilendirilmiştir. Brooks ve ark. ${ }^{31}$ yapmış oldukları çalışmada yüksek riskli geçmişi olan ergenlerde umutluluk ve madde kullanımı arasındaki ilişkiyi değerlendirmiştir. Umut düzeyi yüksek olan gençlerin ağır epizodik içme, günlük tütün kullanımı, yakın zamanda veya ömür boyu esrar kullanımı ve güvensiz cinsel istek olasılığında \%50-58 oranında azalma olduğu saptanmıştır. Böylece umudun psikolojik sağlığı yükselttiği gibi fizyolojik sağlığı da yükseltebileceği görülmektedir. Sağlıklı adolesanın umudu yapılan çalışmalarda stres, benlik saygısı, yaşam doyumu, kültürel farklılıklar, sosyal destek ve sağlıklı yaşam tarzı ile ilişkilendirilmiştir.

Arslantaş ve ark..$^{29}$ çalışmasında yaş, hastalık ve yatış süresi arttıkça umutsuzluğun arttığını; hastalık süresi arttıkça algılanan sosyal desteğin azaldığını; sosyal destek azaldıkça umutsuzluğun arttığını tespit etmiştir. Felder ${ }^{28}$ çalışmasında gastrointestinal/genitoüriner, meme, baş ve boyun veya hematolojik maligniteleri olan dört farklı hasta grubunu ele almıştır. Niteliksel yöntemle yapılan bu çalışma, kanser türüne göre umut veya başa çıkma tarzı kullanımı ve başa çıkma etkinliği düzeylerinde anlamlı bir farklılık bulunmamıştır. Umut düzeyi, hastalıklarının ileri bir aşamada olduğunu bilen hastalarda bile nispeten yüksek bulunmuş olup, her dört grupta da umut ve başa çıkma tarzı kullanımı ile başa çıkma etkinliği arasında pozitif bir ilişki bulunmuştur. Hastalığın terminal evresinde kanser tanısı alan ve hastanede yatan hastaların umut düzeylerini belirlemek amacıyla yapılan çalışmada hastaların umutlarının orta düzeyde olduğu; en yüksek umut düzeyinin manevi alanda, en düşük umut düzeyinin ise hastalığın iyileşmesine yönelik inanç alanında olduğu bulunmuştur. ${ }^{34}$

Martins ve ark. ${ }^{32}$ kanser tanılı çocuk/adölesanlarla yaptıkları çalışmada umudun, anksiyeteyi azalttığını ve yaşam kalitesini artırdığını saptamıştır. Griggs ve Walker15 "Kronik hastalığı olan ergenlerde umudun rolü: bütünleyici derleme" adlı çalışmalarında, 1995-2015 yılları arasında yayınlanan 54 çalışmayı incelemişlerdir. İnceleme sonucunda literatürden yedi tema ortaya çımıştır. $\mathrm{Bu}$ temalar; kronik hastalıkta umut: (1) sağlığı teşvik eder (2) başa çımmayı ve duygusal uyumu kolaylaştırır, (3) yaşam kalitesini arttırır, (4) yaşam ve hastalıkta maneviyat / amaç için esastır (5) benlik saygısını arttırır, (6) esneklikte önemli bir faktördür ve (7) olgunlaşmayı etkiler. Ayrıca bu çalışmada; umut ile ilgili literatürde genellikle yüksek umut seviyesine sahip insanların hedeflerine ulaşmak için birden fazla yol elde edebildiklerini, engellere karşı daha dirençli olduklarını, zorluklar ve başarısızlıklarla daha iyi mücadele edebildikleri öne çıkmaktadır. Ayrıca yüksek umut seviyesine 
sahip olanların depresyonda dâhil olmak üzere kaygı ve psikolojik belirtileri daha etkili bir şekilde yönetebildikleri ifade edilmektedir.

Esteves ve ark. ${ }^{40}$ tarafindan umut araștırmalarına yönelik yaptıkları literatür incelemesinde, çalışmaların değişkenlerini öncül, kesişen ve sonuç değişkenleri olarak üç kategoriye ayırmıştır. Umutla ilişkili olarak çalışılan en yaygın öncül değişkenleri yaş ve cinsiyet olarak belirlemiştir. İncelenen çalışmalarda umudu pozitif olarak etkileyen en yaygın kesişen değişkenler; sosyal destek, benlik saygısı, iyimserlik, gelecek zaman algısı, öz yeterlik, maneviyattır. Umudu negatif olarak etkileyen değişkenler; stres, umutsuzluk, depresyon ve kaygı olarak belirlenmiştir. Çalışmada en yaygın pozitif sonuç değişkenleri; yaşam doyumu, sağlık uygulamaları, iyi oluş, hedef, akademik başarı, pozitif duygulanım iken, en yaygın negatif sonuç değişkeni olarak içselleștirilmiş/dışsallaştırılmış davranışlar ve negatif duygulanım olarak belirlenmiştir. Araştırmacılar öz yeterliğin sağlıklı ergenlerde umutla zayıf bir ilişkiye sahip olduğu ve kanser tanısı almış ergenlerde umutla orta derecede güçlü veya güçlü bir ilişkiye sahip olduğu sonucuna varmışlardır. Hasta adölesanın umudu ise yapılan çalışmalarda yaş, hastalığın türü/evresi, hastane yatış süresi, sosyal destek, maneviyat, anksiyete, öz yeterlik ve hastalığın iyileşmesine olan inancı ile ilişkilendirilmiştir.

Sonuç olarak, pek çok disiplin tarafından çalışılmakta olan umut kavramı; bu konunun önemine ilişkin farkındalığın artırılması, bireyler için destekleyici bir iç faktör olan umudun harekete geçirilmesi, bireylerin güçlendirilmesi ve zorlu durumlarda baş etme yeteneklerinin geliştirilmesi yönünden önem taşımaktadır. Adölesan dönemde pek çok olumsuz etken insan hayatını ciddi anlamda zorlamaktadır. Topluma hizmet veren özellikle birinci basamak sağlık hizmetlerinde görev alan hemşirelerin adölesanların zorluklar karşısında harekete geçirebilecekleri koruyucu faktörleri belirleyerek, adölesanları geleceğe hazırlamakla yükümlüdür. Umut anlık zorluklarla mücadele edebilme ve üzüntü durumunu üstünden atabilmede iyileștirici bir faktördür. $\mathrm{Bu}$ bağlamda hemşireler koruyucu rolünün yanında güç veren iyileștirici/tedavi edici bir konumda olduğunu unutmamalıdır. Hemşireler, kişilerarası bağlılık, cesaret ve sakinlik, ulaşılabilir hedefler belirleme, manevi bir temel kullanma, anları harekete geçirme ve bireysel değerlerini vurgulama açısından adölesanlarda umut uyandirmada anahtar bir konumdadır. Umudu zenginleștiren ve nazik iletişim becerileri olan hemşireler, bireylerin başa çıkma durumlarını geliştirmelerine yardımcı olabilir.9,36,40

$$
\text { Umudun önemine ilişkin }
$$

farkındalığın artırılması, bireyler için destekleyici faktör olan umudun aktive edilmesi, bireylerin güçlendirilmesi ve zor durumlarda baş etme yeteneklerinin geliştirilmesi yönünden önem taşımaktadır. Hizmetin yönünü belirlemede ve hizmetin sunumunda etkin bir şekilde yer alan sağlık çalışanları adölesan döneminde umudun gelişimsel durumuna uyumda ve bu süreçte karşılaşabileceği sorunların çözümünde anahtar rol oynamaktadır. Sağlığın korunması ve geliştirilmesi, profesyonel hemşireliğin özünde yer aldığından umudun anlamı, umut kaynakları, umut düzeyleri ve bunları etkileyen faktörleri bilmesi gerekir. $\mathrm{Bu}$ bilgiler ışığında etkili girişimler geliștirmek ve bireylerin umutlarını artırmaya yönelik stratejiler kullanarak bu kavramı sürdürmekle ilgili sorumlulukları olduğunu göz ardı etmemelidir. Sağlıklı veya hasta adölesanların gelişim aşamalarına göre umudu artırmak için hemşireler tarafından özel yapılandırılmış müdahalelerin geliştirilmesine ihtiyaç vardır. Bireylerin hayat yolculuğunda karşı karşıya kaldıkları çeşitli zorluklar olabilmektedir. Bireylerde sağlığın gelişimi ve yeterliğini teşvik etmek, en az problemleri önlemek kadar değerlidir. $\mathrm{Bu}$ açıdan çocukluktan itibaren umudun beslenmesi ve desteklenmesi psikolojik olarak sağlam toplumların ortaya çıkması için son derece önemlidir.

Mevcut çalışmalar umudun hem sağlıklı hem de herhangi bir sağlık sorununa sahip adölesanlarda önemli bir yere sahip olduğu vurgulanmaktadır. Umut ile ilgili çalışmalar sıklıkla gözlemsel çalışmalar olup; sağlık algısı, sağlığı koruma ve geliştirmede 
öz sorumluluk, hastalıkla mücadelede umudun rolü gibi konulara ağırlık veren çalışmalardır. Gelecekteki çalışmaların analitik yaklaşımla umut ve sağlık/hastalık ilişkisinin nedenselliği üzerine yoğunlaşması ve ayrıca randomize kontrollü çalışmalarla umudu artıran girișimlerin etkilerinin değerlendirilmesi önerilebilir.

Yazar katkısı: Araștırmacılar planlama, uygulama, çözümleme ve yazım aşamalarına eşit derecede katkı vermiştir.

Çıkar çatışması/Mali destek: Yazarların çıkar çatışması bulunmamaktadır. Çalışmaya destek olan herhangi bir resmi veya özel kurum yoktur.

\section{Kaynaklar}

1. Sağlık Bakanlığı. Birinci basamak sağlık çalışanları için ergen sağlığına ve sorunlarına yaklaşım cep kitabı. Erişim yeri:

https://hsgm.saglik.gov.tr/depo/birimle r/cocuk_ergen_db/dokumanlar/yayinlar /Kitaplar/Birinci_basamak_saglik_calisa nlari_icin_ergen_sagligina_ve_sorunlarin a_yaklasim_cep_kitap.pdf. 12 Haziran 2020'de erişildi.

2. World Health Organization. Global Health Estimates (GHE). Erişim yeri: https://www.who.int/maternal_child_a dolescent/data/causes-deathadolescents/en/ 5 Haziran 2020'de erişildi.

3. World Health Organization. Maternal, newborn, child and adolescent health. Erişim yeri:https://www.who.int/maternal_chi ld_adolescent/adolescence/universalhealth-coverage/en/ 5 Haziran 2020'de erişildi.

4. Türkiye İstatistik Kurumu. İstatistiklerle Gençlik. Erișim yeri:http://www.tuik.gov.tr/PreHaberB ultenleri.do?id=30723 $2 \quad$ Haziran 2020'de erişildi.

5. Griggs S, Crawford SL. Differences in hope, core self-evaluations, emotional well-being, and health risk behaviors in freshman university students. Nursing Forum. 2019;54(4):505-512. doi:10.1111/nuf.12364

6. Hammer K, Mogensen O, Hall EOC. The meaning of hope in nursing research: a meta-synthesis. Scand J Caring Sci. 2009;23(3):549-557.

doi:10.1111/j.1471-6712.2008.00635.x

7. Yarcheski A, Mahon NE. Meta-analyses of predictors of hope in adolescents. Western Journal of Nursing Research. 2016;38(3):345-368. doi:10.1177/0193945914559545

8. Snyder CR. Hope theory: rainbows in the mind. Psychological Inquiry. 2002;13(4):249-275.

9. Öz F. Sağlık alanında temel kavramlar. Ümit ümitsizlik. 2.baskl, Ankara, Mattek Matbaacılık Bas. Yay. Tic. Ltd. Şti. 2010:189-224.

10. Larsen D, Edey W, Lemay L. Understanding the role of hope in counselling: Exploring the intentional uses of hope. Counselling Psychology Quarterly. 2007;20(4):401-416. doi:10.1080/09515070701690036

11. Beck AT, Weissman A, Lester D, Trexler L. The measurement of pessimism: The Hopelessness Scale. Journal of Consulting and Clinical Psychology. 1974;42(6):861-865.

12. Quan P, Huang D, Yu Y, Liu R. Mediation role of hope between self-efficacy and subjective well-being. Iran Journal Public Health. 2016;45(3):390-391.

13. Bilgiç Ş, Temel M, Çelikkalp Ü. Hemşirelik öğrencilerinin öğrenilmiş güçlülük, öz yeterlilik ve umut düzeylerinin değerlendirilmesi: Tekirdağ örneği. Sağlık ve Hemșirelik Yönetimi Dergisi. 2017;4(3):117-126.

doi:10.5222/SHYD.2017.117

14. Griggs S, Walker RK. The role of hope for adolescents with a chronic illness: an integrative review. Journal of Pediatric Nursing. 2016;31(4):404-421. doi:10.1016/j.pedn.2016.02.011

15. Tarhan S, Bacanlı H. İlkokuldan üniversiteye umut kavramının 
tanımlanması üzerine nitel bir çalışma. Eğitimde Nitel Araştırmalar Dergisi. Journal of Qualitative Research in Education. 2016;4(2):86-112.

16. Çankaya ZC, Meydan B. Ergenlik döneminde mutluluk ve umut. Elektronik Sosyal Bilimler Dergisi. 2018;17(65):207-222.

doi:10.17755/esosder.316977

17. Weis R, Speridakos EC. A Meta-Analysis of hope enhancement strategies in clinical and community setting. Psychology of Well-Being: Theory, Research and Practice. 2011;1:5. doi:10.1186/2211-1522-1-5

18. Snyder C, Harris C, Anderson J, Holleran $S$, Irving L, Sigmon S, vd. The Will and the Ways - Development and Validation of an Individual-Differences Measure of Hope. Journal of Personality and Social Psychology. 1991;60(4):570-585.

19. Tarhan S, Bacanlı, H. Sürekli umut ölçeği'nin Türkçe'ye uyarlanması: Geçerlik ve güvenirlik çalıșması. The Journal of Happiness \& Well-Being. 2015;3(1):1-14.

20. Snyder CR, Hoza B, Pelham WE, Rapoff M, Ware L, Danovsky M, vd. The Development and Validation of the Children's Hope Scale. Journal Pediatric Psychology. 1997;22(3):399-421. doi:10.1093/jpepsy/22.3.399

21. Atik G, Kemer G. Çocuklarda Umut Ölçeği'nin psikometrik özellikleri: Geçerlik ve güvenirlik çalışması. Elementary Education Online. 2009;8(2):379-390.

22. Hinds PS. Inducing a definition of 'hope' through the use of grounded theory methodology. Journal of Advanced Nursing. 1984;9(4):357-362. doi:10.1111/j.1365-

2648.1984.tb00384.x

23. Esenay FI, Conk Z. Ergenler için Umutluluk Ölçeği: Geçerlik-güvenirlik çalışması. Ankara Sağlık Bilimleri Dergisi. 2012;2:230-248.

24. Schrank B, Woppmann A, Sibitz I, Lauber C. Development and validation of an integrative scale to assess hope. Health Expectations. 2011;14(4):417-428. doi:10.1111/j.1369-7625.2010.00645.x

25. Sarıçam H, Akın A. Bütünleyici umut ölçeğinin Türkçeye uyarlanması: geçerlik ve güvenirlik çalışması. Adıyaman Üniversitesi Sosyal Bilimler Enstitüsü Dergisi. 2013;6:291-302.

26. Aslan Ö, Sekmen K, Kömürcü Ş, Özet A. Kanserli hastalarda umut. Cumhuriyet Üniversitesi Hemşirelik Yüksekokulu Dergisi. 2007;11:18-24.

27. Herth K. Development and refinement of an instrument to measure hope. Scholarary Inquirity Nursing Practice. 1991;5(1):39-51.

28. Felder EF. Hope and coping in patients with cancer diagnoses. Cancer Nursing. 2004;27(4):320-324.

doi:10.1097/00002820-20040700000009

29. Arslantaș H, Adana F, Kaya F, Turan D. Yatan hastalarda umutsuzluk ve sosyal destek düzeyi ve bunları etkileyen faktörler. Florence Nightingale Hemşirelik Dergisi. 2010;18:87-97.

30. Ardahan F, Genç S, Uludağ AH. Tedavisi tamamlanmıs meme kanserli kadınlarda düzenli fiziksel aktivitenin hastanın yașam doyumu ve umut düzeyine etkisi. Türkiye Klinikleri Journal of Sports Sciences 2015;7(2):41-47.

31. Brooks MJ, Marshal MP, McCauley HL, Douaihy A, Miller E. The Relationship Between Hope and Adolescent Likelihood to Endorse Substance Use Behaviors in a Sample of Marginalized Youth. Substance Use \& Misuse. 2016;51(13):1815-1819. doi:10.1080/10826084.2016.1197268

32. Martins AR, Crespo C, Salvador A, Santos S, Carona C, Canavarro MC. Does hope matter? Associations among selfreported hope, anxiety, and healthrelated quality of life in children and adolescents with cancer. Journal of Clinical Psychology in Medical Settings. 2018;25(1):93-103. doi:10.1007/s10880-018-9547-x 
33. Lina Mahayati S, Allenidekania, Happy H. Spirituality in adolescents with cancer. Enfermeria Clinica. 2018;28 Suppl 1:3135. doi:10.1016/S1130-8621(18)300329

34. Baczewska B, Block B, Kropornicka B, Niedzielski A, Malm M, Zwolak A, vd. Hope in Hospitalized Patients with Terminal Cancer. International Journal Environmental Research and Public Health. 2019;16(20):1-10. doi:10.3390/ijerph16203867

35. Dixson DD, Worrell FC, Mello Z. Profiles of hope: How clusters of hope relate to school variables. Learning and Individual Differences. 2017;59:55-64. doi:10.1016/j.lindif.2017.08.011

36. Zlotnick C, Goldblatt H, BirenbaumCarmeli D, Dishon Y, Taychaw O, Shadmi E. The impact of adolescents' racial and ethnic self-identity on hope. Health and Social Care in the Community. 2019;27(5):e705-715. doi:10.1111/hsc.12795

37. García-Alandete J, Gallego Hernández de Tejada B, Pérez Rodríguez S, MarcoSalvador JH. Meaning in life among adolescents: Factorial invariance of the purpose in life test and buffering effect on the relationship between emotional dysregulation and hopelessness. Clinical Psychology Psychotherapy. 2019;26(1):24-34. doi:10.1002/cpp.2327

38. Gerard JM, Booth MZ. Family and school influences on adolescents' adjustment: The moderating role of youth hopefulness and aspirations for the future. Journal of Adolescence. 2015;44:1-16. doi:10.1016/j.adolescence.2015.06.003

39. McCoy H, Bowen EA. Hope in the Social Environment: Factors Affecting Future Aspirations and School Self-Efficacy for Youth in Urban Environments. Child and Adolescent Social Work Journal. 2015;32(2):131-141. doi:10.1007/s10560-014-0343-7

40. Esteves M, Scoloveno R, Mahat G, Yarcheski A, Scoloveno MA. An integrative review of adolescent hope. Journal of Pediatric Nursing. 2013;28(2):105-113. doi:10.1016/j.pedn.2012.03.033 